\title{
Shaping of Cities' Identities with Cultural Uniqueness: Handcraft Shops and Night Bazaar in Chiang Mai, Thailand, and Hanoi Old Quarter in Vietnam
}

\author{
Yekti Maunati \\ Research Center for Area Studies, The Indonesian Institute of Science, Jakarta, Indonesia \\ $<$ yektimaunati59@gmail.com>
}

\begin{abstract}
A city usually has its own identity and cultural uniqueness with the markers of identity perhaps varying among museums, monuments, temples, theatre buildings, handcraft and traditional shops/markets and night bazaars and historical heritage sites, to mention a few. It is very common for cities in mainland Southeast Asia, like Bangkok, Chiang Mai, Phnom Penh, Luang Prabang and Hanoi to have handcraft markets/shops as well as night bazaars selling various handcrafts attributed to one ethnic group or another. Those handcraft shops/markets and night bazaars are often at least partly related to the promotion of tourism. However, they do not only exist for the sake of tourism, since the promotion of cultural uniqueness as the identity of a city is related to the feeling of pride and the very soul of the city. This paper will discuss the existing handcraft markets/shops and night bazaar in Chiang Mai (Thailand) as important elements of the city's icons and the Hanoi Old Quarter, a historical heritage area in Hanoi, where handcraft shops, night market, cafés and many more venues are integral to the identity of Hanoi. The fieldwork was conducted in Chiang Mai in 2004, 2005, 2009 and 2016 for a few days and in Hanoi in 2006, 2017, 2018 for a few days, especially using qualitative research. The discussion is divided into three parts: the First, giving a brief review of the identity of a city; the Second, touching on the issue of how the handcraft shops and the Night Bazaar in Chiang Mai are seen as the city icons; and Finally, the shaping of the Hanoi Old Quarter as Hanoi's cultural icon/identity.
\end{abstract}

Keywords: cultural uniqueness, Chiang Mai night bazaar, Hanoi Old Quarter, and city identity

\section{Cultural Uniqueness as the Identity of a City: A Brief Review}

As cultural identity is socially constructed, cultural uniqueness could be selected to be one of the markers of a city's identity, giving rise to wide argument on the construction of cultural identity.[1],[2],[3],[4],[5],[6] Wen and White (2020) note that construction of cultural and national identity can be 
seen from the landscape. In relation to the construction of identity, this is often linked to particular processes and different historical experiences. In the case of a city, it has also its own cultural uniqueness that can become a marker of the identity of that city. Cultural uniqueness can originate from different elements, ranging through physical, natural, historical, as well as material cultures. The Opera House, for instance, is often associated with Sydney. The Blue Mosque, Hagia Sophia and Grand Bazaar, are icons of Istanbul. The Eifel Tower is the icon of Paris, while Singapore has been linked with the Merlion. Of course, those mentioned above have not been the only icons of such cities where there are often many other cultural icons as well. Neverthless, each city has constructed and particularly promoted one as its own icon or identity.

In the process of the contruction of a city identity, the city may have a different priority in selecting the element of identity. Indeed, the creation of markers of identity can also vary from one city to another. The dynamic of the selection of a marker of identity can also happen for particular reasons, including promoting a certain cultural uniqueness, adjusting with the recent context and situation and lauding a particular historical aspect.

Donboli, et.al., note that the identity of Iranian cities constitutes many elements, where artefacts came to be the first priority, followed by natural and human aspects.[7] Based on study in three Iranian cities, Isfahan, Yazd and Shiraz, they attempt to understand the important role in the identity of Iranian cities, deciding:

Urban identity in most of eastern countries consists of a series of cultural events in different periods with the aim of preserving the past. [7]

Donboli, et.al. further say 'In all historical stages, each social identity, created in a city has many reflected physical identities of that city'. They believe that urban identity is a kind of representative reality deriving from the past to the present that constructs the city. Further noting:

Urban identity is defined with the natural and artificial elements and socio-cultural characteristics of a city and the environment.[7]

Similarly, construction of city identity has taken place in Indonesia with there also being the idea to represent uniqueness of culture by using certain material culture to create its cultural uniqueness. Each city has attempted to create its own uniqueness as its identity. For the purpose of tourism, for example, in Indonesian cities, especially the capitals of provinces, have created their own cultural uniqueness by using certain cultural icons in certain architecture. In relation to the above issue, Kipp, for intance, pinpoints:

Indonesia's policies on culture and ethnicity must be seen in terms 
of these contradictory demands to minimize the destabilizing potential of ethnicity, and also to use traditional cultures for economic and integrative ends.[8]

Further arguing that the policy of the New Order Government was to create 'a single cultural type for each province'.[8] In line with this policy, we can observe many cities in Indonesia that have constructed their identities. In West Sumatra, the city of Bukittinggi, for intance, has become known for its Jam Gadang (big watch), while Bandung has Gedung Sate (sate building) with a historical narrative. Of course, both Jam Gadang and Gedung Sate are not the only markers of identities of Bukittinggi and Bandung since there are many other elements to represent the icons of those two cities. Additionally, Bukittinggi has been well-known for its traditional market of popular embroidery materials.

In East Kalimantan, Dayak material culture is used to represent East Kalimantan even though the Dayak are a minority of the population.[9] In Samarinda, the capital city of East Kalimantan, for example, there are many buildings with Dayak material culture representations.[10] Indeed the cultural elements to represent some cities in Indonesia have been promoted, not only for the sake of tourist attraction but also to show the uniqueness of its cultural heritages. In fact the selection of such cultural elements can be subject to change for many reasons, including adjustment to new demands as well as government policy.

Cultural uniqueness is most important for elements of city identity. According to Wojnarowska (2011) the formation of the city identity in Eastern Germany was made by conducting a restoration of historical buildings especially those that had been destroyed.[11] Apart from showing a city's identity, this process also created projects for the development of the city. Indeed, the historical aspect is a very important element in the process of the construction of city identity.

Kahn (1997) sums up that the renovation of streets as heritage in Georgetown is to create an image of Malaysian modernity. The city renovation is not only to show the city identity, but could be more than that for Malaysia. Furthermore Kahn (1997) gives an example of the development of a particular street in Georgetown, which has less to do with the tourism industry or the encounter between the West and the East, and more with economic, political and cultural developments in Malaysia. In this case, the state government's efforts to conserve important heritage sites is directly linked to the government's intention to show the international community that Malaysia is a developed and attractive country.[12]

The construction of a city identity can relate with a number of different reasons and could utilise numerous 
cultural elements. Traditional markets have been very important as cultural identities or icons of certain cities. Such traditional markets have their own uniqueneses in terms of architecture, design, products sold and so forth. Indeed, traditional markets have become important aspects of cities' identities.[13] In the Islamic worlds, the architecture of the markets is equally as important as the uniqueness of the market. There may be adjustments in many ways, but these are still showing its uniqueness. Hmod (2017) argues that cities are in need of adjustment to modern life by using architecture and urban heritage for keeping the identity and the uniqueness of the region.[13] He further pinpoints that today having traditional markets has become a source of pride of some Islamic cities in many parts of the world where the contemporary markets have kept their uniqueness as identity while meeting the needs of the community in certain ways.

Hmod (2017: 264) notes that normally in the Islamic cities, the locations of markets are in the heart of the cities near the mosques. The functions of traditional markets are to provide places for people to enjoy, be entertained and have social association so that people usually spend more time there. In terms of architecture, markets are built with certain considerations like climate and cultural and religious elements. Hmod notes 'types of traditional markets: Al Bazaar, caravanserai, the Qaysariyya'.[13] With the Grand Bazaar in Istanbul an example of a traditional market.

Indeed, the traditional and unique architecture of traditional markets has become the cultural identity of Islamic cities today. The Grand Bazaar in Istanbul is one of the cultural icons in that city. Apart from keeping the heritage of markets' unique architecture, the existence of traditional markets has been important in showing the urban heritage of certain cities. Besides the uniqueness in architecture, traditional markets often have their own exceptionality in terms of goods traded, grouping of types of goods and so forth.

Night bazaars/night markets are also unique to certain cities. Many cities in Mainland Southeast Asia are wellknown for their night bazaars or night markets being the icons of those cities.

\section{Handcraft Shops and Night Bazaar in Chiang Mai, Thailand}

In Thailand, traditional markets and night markets/bazaars can be found in many cities, including Bangkok, Chiang Mai, Chiang Rai and Pitsanulok, to mention a few. Indeed, night markets/ bazaars have been the icons of those cities and function to promote tourism as places where visitors can enjoy spending time in the evening for dining as well as shopping or simply for leisure. As the Chiang Mai handcraft shops and Night Bazaar have always been very popular, below I will focus on 
those.

Located in Northern Thailand, information about Chiang Mai will produce many interesting places to visit with one, the Night Bazaar a particular icon of the city with everybody who visits Chiang Mai expected to spend time to visit the famous Night Bazaar of Ching Mai.

Maunati (2004) illustrates that Chiang Mai is very popular as a tourist destination in Thailand where there are many tourist attractions. Gazing at minority locations and trekking in the mountains have been parts of the starting points for the promotion of the tourist industry in Chiang Mai and many Khmer temples in the northeast of Thailand are also being promoted. Despite those attractions, however, culture and handcrafts are very important elements for the promotion of tourism in Chiang Mai.[14]

Maunati further notes:

The hill tribes themselves have been promoted for their material cultures, especially in the form of handcrafts used in their ceremonies or feasts. In the Night Bazaar of Chiang Mai, we saw many Akha ladies offering their handcrafts, especially ladies' traditional hats, decorated bags and jewellery (particularly bracelets and necklaces). The ladies wear the highly decorated with metal coins which make the sound 'cring..cring', traditional hats. Originally, the Akha used silver for the decorations, but today they often use cheaper metals as a replacement for the silver. They walk along the night bazaar offering their handcrafts to visitors. Usually, they touch people who walk in the Night Bazaar or offer the handcrafts to the people having dinner in the restaurants. They do not enter the restaurants but offer their handcrafts to the people sitting close to the pavements. When I was having dinner in a restaurant at the Night Bazaar, I observed an Akha lady offering her handcrafts to westerners who happened to be sitting near the barrier separating the restaurant from the pavement along which people walk back and forth to browse among the stalls located along the edge of pavements.[14]

I have visited Chiang Mai and especially the Night Bazaar several times since my first visit in 2004, in 2005, 2009, and 2016. Based on my observations, especially in 2016, the Night Bazaar area is larger than in previous years with more traders.

The Night Bazaar of Chiang Mai is indeed one of the important icons of the city of Chiang Mai as can be illustrated by several points. First, if we search for Chiang Mai, we will find the information about the Night Bazaar as one of the main attractions or places of interest to be visited for those who come to Chiang Mai:

Chiang Mai Night Bazaar or just Night Bazaar (Thai: ไนท์บาซาร์, Nai Basa) is directly east of the city moat, between it and the Ping River, on Chang Khlan Road, between Tha Phae and Sridonchai Roads. It is known for its handcrafts and portrait paintings. There are also jewellery, toys, clothing, and high tech items such as CDs and DVDs. The market is one of the most popular tourist attractions in Chiang Mai.[1] First owned by Chinese merchants, it grew in size as more commercial buildings 
were built and now is no longer owned by a single group of people but by many owners, most of whom are Thai.[19]

Indeed, promotion of the Night Bazaar of Chiang Mai can be found in many different forms, especially in online and hardcopy Chiang Mai brochures. The extension of the Night Bazaar can be observed in comparison with previous years. Based on my observations on my last visit in 2016, there were many traders along the main road of the Night Bazaar, either in the form of shops or in the stands along the pavement. There were many food areas as well, where visitors could get different types of foods, ranging from Thai, through Asian, to western food. Apart from food, various handcrafts from different ethnic groups can be found easily. This is not surprising since many minorities live in Northern Thailand where Chiang Mai is located.

During our stay in Chiang Mai , the Night Bazaar was very crowded at around dinner time at 7-8.30 pm. If we visited earlier, like $6 \mathrm{pm}$, the crowd had not yet arrived. We could enjoy the situation of the Night Bazaar and walk around easily. However, at dinner time the crowd could be observed especially in the food places along the main road though apart from those food places we could also find many restaurants throughout the Night Bazaar area.

Clearly, the Night Bazaar is the icon of Chiang Mai. Acccording to information gathered in Chiang Mai, we were told that visitors will spend time in the Night Bazaar during their visit in Chiang Mai as it is a central destination for Chiang Mai. Often, there is a kind of event/festival held there which adds to the attraction. Of course the Night Bazaar is not the only icon of Chiang Mai and people can also find handcraft shops in the city with one of these shops even located in the main road of the Night Bazaar. When I visited Chiang Mai the first time, this handcraft shop was lively with many visitors buying souvenirs. The shop has several levels and on the ground floor level people could buy T-shirts with different designs like hand made paintings of flowers. Other than these, we could find many handcrafts from minority people, like the Hmong, Akha and so forth. On the first level we could find handcrafts like pottery or painted pots and different precious stones in the forms of different types of jewellery like rings, earrings, pendants, could also be found there; from the cheap to expensive ones. However, when I visited Chiang Mai in 2016, along the main road there were more traders but the traditional shops were rather quiet with few customers. Indeed, there has been a change with along the main road there being many impermanent shops with various goods, including T-shirts, plastic stones and so forth.

Basically, night markets or night bazaars are very common in the cities of Thailand like Bangkok, Chiang Mai, 
Phayo and Pitsanulok. Nevertheless, the Chiang Mai Night Bazaar is one of the most popular and one of the markers of Chiang Mai identity.

\section{Hanoi Old Quarter and Its Surroundings}

Hanoi has many cultural icons, including the Temple of Literature, the Museum of Ethnology, theatre building, the silk village and handcraft shops surrounding Lake Hoan Kiem within the area of the Hanoi Old Quarter. In this part I will focus on the Hanoi Old Quarter and its surroundings since this is a unique and well-known area exclusive to Hanoi, subject to many promotions from different sources both online or in hard copies of brochures. For example, for online promotion there is '20 must-visit attractions In Hanoi, Vietnam', apart from the Imperial Citadel of Thang Long, the Thang Long Water Puppet Theatre, the Dong Xuan Market, the Hanoi Opera House, the Temple of Literature, the Museum of Ethnology, One Pillar Pagoda, the West Lake, the Ho Chi Minh Museum, the Vietnam Military Museum, the Long Bien Bridge, the Hanoi Old Quarter and Hoan Kiem Lake have been promoted as Hanoi tourist destinations.[20] For further illustration, the Hoan

Kiem Lake is described as follows:

Hoan Kiem Lake (Turtle Lake) is a popular hangout spot for locals and foreigners. On an island in the centre lies Ngoc Son Temple, linked by a graceful red bridge. It serves as a fabulous background for photos, and if you're lucky you might catch couples doing their engagement photo shoots here too.[20]

While the Hanoi Old Quarter is given this description:

The Hanoi Old Quarter is a lively area where travellers can enjoy many fine examples of colonial architecture packed along narrow streets. This is the city's ultimate shopping spot, and is full of cafés and restaurants to indulge in some delicious Vietnamese cuisine.[21]

Another source promotes the Hanoi Old Quarter with a more detailed illustration of the area:
For many visitors to Vietnam's capital, the major attraction is strolling the streets of the city's ancient core. This labyrinthine quarter of narrow alleys is the commercial heartbeat of town and has a history that stretches back 1,000 years. ... If you look up while you're wandering, the area has plenty of vernacular shophouse architecture, where merchants would traditionally live above their shops in very long but narrow two-storey dwellings, squeezed together on the alleyway rows. The backstreets here are a great opportunity to soak up the buzz of Hanoi street life. As well as there being plenty of street food on offer and lots of pavement vendors selling fruits and vegetables, there are also stalls selling traditional medicines and Buddhist religious trappings. A relic of French Colonial rule, right in the heart of the old town quarter, St. Joseph's Cathedral (Nha Tho Street) was built in 1886 and is a fine example of neo-Gothic architectural style.[15]

On top of these promotions for tourism purposes, some studies on the Hanoi Old Quarter have been made by scholars. For example, Waibel (2004) who focuses on 'The Ancient Quarter 
of Hanoi - A Reflection of Urban

Transition Processes' in (2004:31) and notes that Vietnam's oldest market, retail and trade, is in the Hanoi Ancient Quarter . Citing from Templer (1998: 229) and Boudarel and Ky (2002), he says:

It is the heart and soul of the city, a prized legacy of Hanoi's past as well as unique part of the Vietnamese urban identity and national mythology.[16]

Waibel (2004) explains the history of the Hanoi Ancient Quarter and the issues faced by those traders and entrepreneurs in the area, from time to time with different powers involved. The preservation of the area has been done with certain challenges at different times and under different powers. Meanwhile, the establishment of mini hotels has been part of the transformation now seen. In 1988, houses were also being used as outlets for trading. The price of land was very high. After the Doi Moi policy which saw the opening up of the economy and impacted on the growing of businesses with restaurants and public consumption growing as well.

Another scholar who studies the Ancient Quarter of Hanoi, Turner, (2009) focuses on 'Hanoi's Ancient Quarter Traders: Resilient Livelihoods in a Rapidly Transforming City' and attempts to understand the impact of historical, political and economic policies as well as economic reform for traders in the Hanoi Old/Ancient
Quarter. Traders and entrepreneurs have been there since the $13^{\text {th }}$ century experiencing French rulers as well as the First and the Second Indochina Wars. Facing many hard times, traders have found various strategies to survive. [17] We can see now that the Hanoi Old Quarter continues to be the place for traders and entrepreneurs to do their businesses. Indeed, the Hanoi Old Quarter has its unique history and continues to be the icon of Hanoi.

Based on my observations, the Hanoi Old Quarter and its surroundings, especially the Hoan Kiem Lake have become an important identity of Hanoi. If you take a tour to Hanoi, you will visit this area to find some souvenirs and to enjoy the unique situation. In a tour with an Indonesian tour agency in 2018, apart from Ho Chi Minh City and Halong Bay, we visited Hanoi and stayed at a Mini Hotel in the Hanoi Old Quarter. The hotel is very near the night market in this area and at night we could hear music from opposite the hotel. In our free time we wandered around the Hanoi Old Quarter: along the Hang Gai, Cau Go, Dinh Tin Hoang streets where we found many handcraft shops, restaurants and cafés. This area is near the Hoan Kiem Lake and a place for people to enjoy their shopping, eating and viewing of the lake. From my observations, this area is always crowded with many people: local and international visitors. When we visited this area, we could buy Vietnamese 
souvenirs like silk scarves, silk table cloths, different types of wall paintings on different surfaces, like bamboo and textiles (including silk) and Vietnamese women's and men's clothes. If we walked along this area, like along the Hang Gai Street, we found different shops selling silk scarves of different qualities and prices, from only 100 VND (Vietnamese Dong), as well as certain shops that sell silk scarves of very fine quality priced at thousands of VND. Indeed, there is choice for people to buy Vietnamese silk as Hanoi and Vietnam in general, are famous for silk. Meanwhile, for affordable souvenirs, people could buy scarves for around 100-120 VND in many souvenir shops along Hang Gai Street. In Dinh Tin Hoang Street, there are restaurants, especially in the corner building where people can enjoy dinner on the upper levels of the building. People can view Hoan Kiem Lake at night which is very beautiful with colourful lighting. Apart from Vietnamese restaurants, there is a Thai Restaurant which is very well-known too, providing Thai cuisine, like gaeng keow wan gai (Thai green chicken curry), Pad Thai (Thai style stir - fried noodles), tom yum goong (hot and sour soup with shrimp), khoo Pad (Thai style fried rice) and so forth. On the ground floor level, there is a minimarket that provides various Vietnamese coffees and Vietnamese snacks. In front of this minimarket there is a money changer. One brand of the well-known Vietnamese coffee has five levels, from number 1 until 5 that differentiates the level of strength of the coffee. Basically, in this area, visitors can find many things: souvenir shops, restaurants, a minimarket and so forth.

The last time in the same year, 2018, when I visited Hanoi with the fieldwork Team, on Saturday night, I could hear music and see people dancing on the shore of the lake, in the Dinh Tin Hoang Street, a wide area in front of the corner building with its many restaurants. I have visited Hanoi and this area a few times, but it was only in 2018 that the music and dance together were performed there; on previous visits, I did not observe this event. People spend their weekends in this area, both tourists and local people. The Lake is surrounded by a beautiful garden with a lot of different flowers especially during Spring when there is a flower festival when visitors can see the showcase of blossoms.

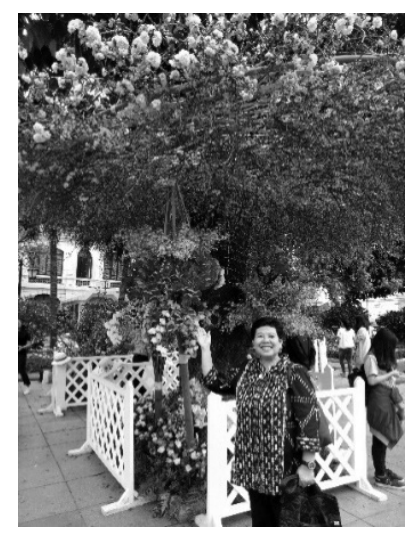

Fig. 1. Flower festival (Author's personal collection) 


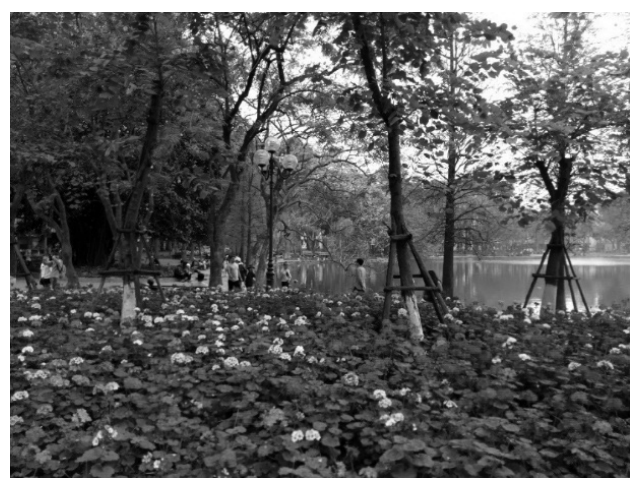

Fig. 2. Garden surrounding Hoan Kiem Lake (Author's personal collection)

From an old coffee shop in this area visitors can enjoy the view of Hoan Kiem Lake while drinking authentic coffee. When we visited it was packed with people and at first we could not find seats. After a while we did get a table in the corner and from the veranda could see the Lake. As the coffee shop is located on the second floor of a multistorey building, to reach it we had to climb a narrow stair case at the back. According to our translator, this coffee shop has been there for a long time and amongst the local people it is believed to serve the most authentic Vietnamese coffee. This was the first time I visited this old coffee shop as previously I had never heard about it until our translator, who is a local Vietnamese, told us. The taste of the Vietnamese coffee is very strong (see photo 3 ).

There are also night markets along Hang Dao, Hoan Kiem, where visitors can find many things: various handcrafts like those made of silk, food, shoes, clothing and so on. In the night market, the traders put up merchandise tents on

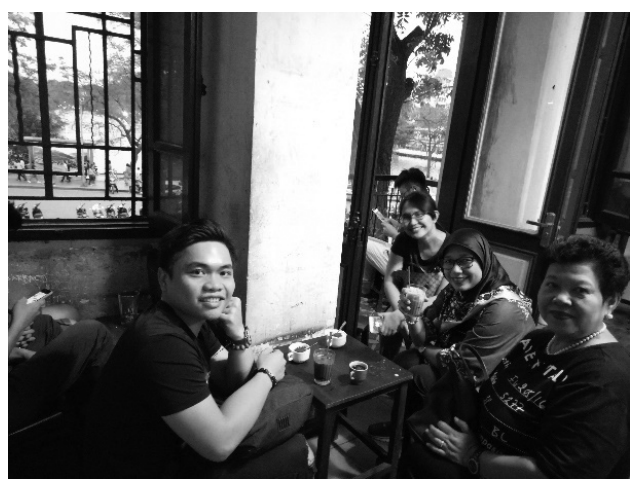

Fig. 3. Old Coffee Shop (Author's personal collection)

the street. The permanent shops along the street are opened at night as well so the visitors can shop both from the street traders and the permanent shops.

Apart from the night market, there are many handcraft shops along the streets, Hang Gai, Cau Go, Hang Thung, etc, in the Hanoi area. Visitors can walk along those streets to find handcrafts, ranging from silk table cloths to silk chair cushions, silk scarves, wooden cups, wall paintings and so forth. As I mentioned previously, there are many shops that sell more expensive things of high quality. Basically, visitors can purchase similar things of different qualities and prices, depending on their choice. Visitors can also bargain in both the permanent shops as well as with night market street traders.

Apart from these, in the wider area of the Hanoi Old Quarter visitors can also seek different restaurants, cafés, mini hotels and a variety of shops. When our team stayed in this area, we could see that every night it was visited 
by many people enjoying the very popular Vietnamese coffee in the many coffee shops, including fancy ones.

Indeed, in this area, we could observe many small open-air coffee places, on the pavements where petty hawkers sell various foods, fruit and handcrafts in many locations. A small, low table for coffee and low chairs on the pavements are a special tradition in Hanoi. The growth of the 'pavement economy' has happened where small traders sell food and drink on pavements.[16],[18] Waibel notes that the development of the pavement economy has become well known in this area which has been in line with the fast growth of retail shops and street hawkers who sell many goods, some commuting from other suburbs. I could observe this pavement economy in this area. The first time, in 2006 when I was staying in a mini hotel in the Hanoi Old Quarter, to do research on tourism, in the morning I always saw, surrounding the hotel, unique petty hawkers, selling Vietnamese coffee, fried snacks, noodle soups and so forth on the pavement. In the morning, while having coffee, customers talked to the traders. This could be observed on many pavements around the narrow streets of the Hanoi Old Quarter. Low, tiny chairs and low coffee tables were provided for customers to sit and enjoy the coffee, food and talk. This model is truly uniquely Vietnamese. Of course, we can find a pavement economy in many places in different countries and coffee traders as well, but the model is different. In Yogyakarta there is a lesehan, where food traders sell their food on pavements in the evenings, by putting down mats for customers to sit on while eating. When I stayed in the area of the Hanoi Old Quarter again in 2017, I saw the pavement economy was still in existence where people could drink and eat as the petty hawkers sold their food and drink on the pavement. Even in narrow alleys I could observe petty hawkers selling coffee and food, like fried bananas, pork and chicken sausages on the overhang of hotels or shops or other buildings. Basically, petty hawkers were not only selling their food or drink on the pavements, but also in the overhang of buildings in the narrow alleys where cars could not pass by; only motorbikes or pedestrians. On other visits in 2018, a similar pattern of pavement economy was still growing in the Hanoi Old Quarter. From the window of a mini hotel, we could observe people having coffee served on the pavement by petty hawkers; laughing and chatting while having coffee.

The Hanoi Old Quarter is unique and has a special place in history. It is indeed an identity of Hanoi that has been promoted widely and continues to be preserved as a unique and historical place. Additionally, it has more attractions from time to time, including flower festivals and dancing places, for 
example, which are clearly contributing to the construction of the unique cultural identity of Hanoi.

\section{Conclusion}

City identity is a construction and the markers of identity can be selected from different elements, including cultural, historical, environmental and natural ones. The markers of identity are subject to change and rely on certain contexts and situations. Historical and cultural elements have been very important points for the process of construction of a city identity.

Both Chiang Mai and Hanoi have their cultural and historical uniqueness, deriving from cultural and historical heritages that have constructed the cities' identities. The Night Bazaar as well as handcraft shops/markets have become very important markers of Chiang Mai identity. This identity has been continuously promoted along with the promotion of tourism in Chiang Mai either online or in hard copy brochures. The Hanoi Old Quarter has similarly been widely promoted for the sake of tourism. Construction of identities or icons of those cities seems to have a close relation with the promotion of tourist attractions.

Apart from the promotion for tourism, today, creating pride for their city and giving a soul to it have been very important processes in the construction of both Chiang Mai and Hanoi cultural icons/identities. The holding of many cultural events in those two areas has contributed to the existence and strengtening of the cultural identity of the cities.[]

\section{References}

[1] Hall, Stuart. 1992. The Question of Cultural Identity. In Stuart Hall, David Held, and Tony McGrew (eds.), Modernity and Its Future. Cambridge: Polity Press in association with Open University.

[2] Eriksen, Thomas Hylland. 1993. Ethnicity \& Nationalism: Anthropological Perspectives. London and Boulder, Colorado: Pluto Press

[3] Kahn, Joel S. 1995. Culture, Multiculture, Postculture. London, Thousand Oaks and New Delhi: SAGE Publications

[4] Picard, Michel. 1997. Cultural Tourism, Nation-Building, and Regional Culture: The Making of a Balinese Identity. In Michel Picard \& Robert E. Wood (eds.), Tourism, Ethnicity, and the State in Asian and Pacific Societies. Honolulu: University of Hawai'i Press.

[5] Wood, Robert E. 1998. Touristic ethnicity: a brief itinerary. Ethnic and Racial Studies. March, 21 (2): 218-241.

[6] Wen, Xiaojing and White, Paul. 2020. "The Role of Landscape Art in Cultural and National Identity: Chinese and European Comparisons". Sustainability 2020, 12, 5472, 
doi:10.3390/su12135472. www.mdpi.com/journal/sustainability. p.1-19

[7] Donboli, Sara, Safari, Aref Agha and Abad, Hossein Kalantari Khalil. 2017. "Components of City Identity: A Review of in Iranian Cities". Current World Environmental. Vol 12, No 2.: 237-249. Journal website: www.cwejounal.org.

[8] Kipp, Rita Smith. 1993. Dissociated Identities: Ethnicity, Religion, and Class in an Indonesian Society. The United States of America: The University of Michigan Press.

[9] Gerke, Solvay. 1997. Ethnic Relations and Cultural Dynamics in East Kalimantan: The Case of the Dayak Lady. Indonesia and the Malay World, (72): 176-187

[10] Maunati, Yekti. 2000. Contesting Dayak Identity: Commodification and the Cultural Politics of Identity in East Kalimantan. Dissertation at La Trobe University. Melbourne: La Trobe University, August 2000.

[11] Wojnarowska, Anna. 2011. "Revitalization of Potsdam's Central Area: Regaining the Identity of the City". European Research and Policy. Vol 18, No 1. Review Articles and Reports. P.89-100.

[12] Kahn, Joel S. 1997. Culturalizing Malaysia: Globalism, Tourism, Heritage, and the City in Georgetown. In Michel Picard \& Robert E. Wood (eds.), Tourism, Ethnicity, and the State in Asian and Pacific Societies. Honolulu: University of Hawai'i Press.

[13] Hmod, Kabila Faris. 2017. "Traditional Market in Islamic Architecture: Successful for Past Experience". Structural Studies, Repairs and Maintenance of Heritage Architecture XV:263-273. WTI Transaction of the Built Environment Vol 171. 2017. WIT Press. www.witpress.com. ISSN 1746-4498 (on-line), accessed 15 September 2020.

[15] Lee, Jess. 2020. 12 Top-rated Tourist Attractions in Hanoi. https://www.planetware.com/ vietnam/hanoi-vie-1-9.htm, May 4, 2020. Accessed 18 sept 2020)

[16] Maunati. Yekti. 2004. "Cultural and Ethnic Tourism in Thailand". Tourism in Thailand: Its Challenges and Opportunities. Jakarta: Research Center for Regional Resources, the Indonesian Institute of Sciences (PSDR-LIPI).

[17] Turner, Sarah. 2009. "Hanoi's Ancient Quarter Traders: Resilient Livelihoods in a Rapidly Transforming City “. Urban Studies. Vol. 46, No. 5/6, Special Issue: Trajectories of the New Economy: Regeneration and Dislocation in the Inner City (MAY 2009), pp. 1203-1221 (19 pages). Published By: Sage Publications, Ltd. https://www.jstor.org/ stable/43198021

[18] Waibel, Michael. 2004. "The Ancient Quarter of Hanoi-A Reflection of Urban Transition Processes. ASIEN. Vol 92, S: 30-48. July 2004.

[19] Forbes, Dean. 1996. Asian Metropolis - Urbaninism and the Southeast Asian City. Melbourne.

[20] Chiang Mai Night Bazaar. 2020. File: Chiang Mai Night Bazaar.jpg|thumb|Chiang Mai Night Bazaar. https://en.wikipedia.org/wiki/Chiang_Mai_Night_Bazaar. Accessed 13 August 2020

[21] (https://theculturetrip.com/asia/vietnam/articles/20-must-visit-attractions-in-hanoi/ accessed 16 sept 2020) 